\title{
Augmentation of Heat Transfer in Pipe Flow Using Plain Twisted Tape Inserts for Different Twist Ratios
}

\author{
Maimonul Karim Chowdhury1, Md. Moniruzzaman Bhuyan², Ujjwal Kumar Deb ${ }^{2 *}$ \\ ${ }^{1}$ Department of Science \& Humanities, Military Institute of Science and Technology, Mirpur Cantonment, Dhaka, Bangladesh \\ ${ }^{2}$ Department of Mathematics, Chittagong University of Engineering \& Technology, Chittagong, Bangladesh \\ Email: *ukdebmath@cuet.ac.bd
}

How to cite this paper: Chowdhury, M.K., Bhuyan, Md.M. and Deb, U.K. (2019) Augmentation of Heat Transfer in Pipe Flow Using Plain Twisted Tape Inserts for Different Twist Ratios. Energy and Power Engineering, 11, 342-354.

https://doi.org/10.4236/epe.2019.119022

Received: August 6, 2019

Accepted: September 22, 2019

Published: September 25, 2019

Copyright $\odot 2019$ by author(s) and Scientific Research Publishing Inc. This work is licensed under the Creative Commons Attribution International License (CC BY 4.0).

http://creativecommons.org/licenses/by/4.0/

\begin{abstract}
The heat transfer augmentation of plain twisted tape inserts for different twist ratios has been studied in this study. The data are conducted using the plain twisted tape insert with five different twist ratios respectively. The range of Reynolds number is considered under a uniform heat flux condition. In the case of simulation, the tapes are made from a stainless steel strip with a thickness of $2 \mathrm{~mm}$. A tubular pipe with $850 \mathrm{~mm}$ U-loop length and twist length of $800 \mathrm{~mm}$ each is considered in our study for simulation. Water is used as working fluids inside the tube for our simulation. The simulation results demonstrate that the important heat transfer parameters including Nusselt number $(\mathrm{Nu})$, friction factor $(\mathrm{f})$ and thermal performance index $(\eta)$ are gradually increased with the increment of the twist ratio and reached at the saturated level while twist ratio is 3.5 , afterward the thermal properties are decreased.
\end{abstract}

\section{Keywords}

Heat Transfer, Twist Ratio, Reynolds Number, Turbulent Flow, Simulation

\section{Introduction}

Nowadays in the industrial arena, the demands for mechanical devices are increasing gradually. For this purpose, the heat enhancement technology related to heat exchanger has drawn more attention to the development of such devices. From several studies, it is found that the augmentation of heat varies with different heat transfer parameter including fluid flow rate, the dimension of pipe, different types of inserts, etc. Automobiles, Solar water heaters, Petrochemical 
Industries, Power plan, shell, and tube heat exchangers, etc. are the main application of the heat exchanger [1] [2]. Significant research work has been done on heat transfer enhancement technology to improve the system. The Heat Transfer techniques similarly promote secondary flow and twisted tape inserts due to their benefit of fixed performance and effectiveness in case of heat enhancement. By utilizing the twisted tape inserts, the flow becomes occlude and subsequently produce eddying due to increasing recirculation area between the closest wall surface and the twisted tape insert. So heat transfer in a tube can be increased by fluid mixing with the help of using inserts [3].

It is seen from recent studies that there are some experimental and theoretical methods have been considered on the enhancement of heat transfer coefficient and friction factor for formal fluid flows inside a tube fitted with different types of inserts to influence a swirl in the fluid flow [4] [5] [6] [7]. The study of Zozulya and Seigel [8] [9] observed that for twisted tape insert in a composite flow structure enhances the rate of heat transfer 2.0 to 3.0 times in comparison to a typical plain pipe.

On the other hand, Noothong et al. [2006] and Murugesan et al. [2009] studied experimentally the effect of different types of twisted-tape with twist ratios of 4.0 and 6.0. They found that enhancement of heat transfer and the Nusselt number increases with decreasing the twisted ratio, while friction factor also increases with decreasing the twisted ratio [10] [11]. In the year 2010, Eiamsa et al. investigated the heat transfer rate, friction factor and thermal enhancement factor of the combined devices of twisted tape and wire coil. It is observed that the heat transfer and friction factor is more efficient in twisted tape than wire coil [12]. In the same year Raju et al. explained the influences of various width twisted tape in the range of $10-26 \mathrm{~mm}$ with the range of Reynolds number $6,000-13,500$, in a circular tube of $27.5 \mathrm{~mm}$ inner diameter. They also compared the enhancement of heat transfer for a smooth tube with the twisted tape inserts and found that the rate increased from $36 \%$ to $48 \%$ [13]. In the same year, $\mathrm{Mu}$ rugesan et al. performed an experiment on heat transfer, friction factor and thermal performance factor characteristics using $\mathrm{v}$-cut twisted tape in a circular tube with twist ratios 2.0, 4.4, and 6.0. Three various combinations of width and depth ratio and also considered in their study. The results have shown that the average Nusselt number and friction factor in the tube with v-cut twisted tape increase with decreasing twisted ratios, width ratios and with increasing depth ratios [14].

In a numerical study done by Guo et al., considering the characteristics of heat transfer and friction factor of a laminar flow in a round tube supplied with center-cleared twisted tape inserts. The thermal performance factor of the tube with typical twisted tape was compared with a tube with center-cleared twisted tape and found the rate of increment from $7.0 \%$ to $20.0 \%$. From the results, they proposed that the center-cleared twisted tape was a promised technique for laminar convective heat transfer enhancement [15]. In the year 2013, B. Salamet 
al., conducted an experimental study to enhance the efficiency of heat transfer for turbulent flow in a circular tube in case of rectangular-cut twisted tape inserts with a constant twist ratio of 5.25. They found that the efficiency of heat transfer is increased by 1.9 to 2.3 times as compared with a plain tube [16].

In 2015, Sivakumar et al. considered a laminar flow study in a circular tube fitted with twisted tape inserts under a uniform wall heat flux boundary condition. They found that the enhancement of heat transfer in a tube with twisted tape inserts was enhanced by $25 \%$ to $30 \%$ compared to that of the plain tube [17]. In the same year, Zhu and Chen et al. mentioned the effect of three kinds of twisted tape like single, multiple and triple. They concluded that the triple twisted tape enhanced the capability of heat transfer from 1.8 to 4.5 times more than the single and double. Besides this, they also have shown that the resistance of fluid flowing inside a pipe is varied from 6.0 to 21.2 times according to the shape of the twisted tape inserts [18]. Most recently Bhattacharya et al. simulate both experimentally and numerically the characteristics of heat transfer in a round tube built-in with twisted tape with the flowing parameters, Reynolds number range 100 - 2000, the twisted ratio and the angle at the entrance of the tube. It was observed that the rate of heat transfer enhanced by increasing the entrance angle and decreasing the twisted ratio. Moreover, the efficiency of heat transfer enhancement decreases with increasing the Reynolds numbers [19].

From the above literature, we found various experimental and numerical methods to enhance the quality of heat transfer technique through a pipe fitted with several types of inserts. In this paper, our goal to present the heat transfers phenomena in a circular pipe using the Finite Element Method (FEM). The FEM based software COMSOL MULTIPHYSICS is used for our numerical simulation. Most of the heat-generating the engine uses a straight portion of the circular tube to emit heat from the engine. Till now no studies have been considered for U-loop pipe to study heat transfer. However, the scenario is different in most practical cases. This study deals with a non-isothermal turbulent flow model for simulation. Emphasis is given on the improvements of the twisted geometry for the rate of heat transfer, friction factor, and thermal performance. The effects of the geometrical shape of twisted tape inserts with different tape ratios 2.9, 3.0, $3.25,3.5$ and 4.0 on the friction factor, Nusselt's number $(\mathrm{Nu})$ and thermal enhancement factor $(\eta)$ are considered. The numerical studies are carried out in turbulent flow for Reynolds numbers in the range of 5,000 - 25,000 under a uniform heat flux environment.

\section{Mathematical Model}

The movement of fluid particles and transfer of heat inside the tube, as well as a prediction of the fluid dynamic phenomena, can be determined by the Computational Fluid Dynamics (CFD). Basically, the CFD method mathematically solves the Navier-Stokes equations within each element of the computational domain. In this Governing the study, we considered the heat transfer phenome- 
na through a pipe for a non-isothermal Turbulent flow and the governing equations which describe the flows are the Continuity Equation and the NavierStokes equations are given below [20].

$$
\begin{gathered}
\frac{\partial \rho}{\partial t}+\nabla \cdot(\rho u)=0 \\
\rho(u \cdot \nabla) u \\
\left.=\nabla \cdot\left[-p I+\left(\mu+\mu_{T}\right)\left(\nabla u+(\nabla u)^{\mathrm{T}}\right)\right]-\frac{2}{3}\left(\mu+\mu_{T}\right)(\nabla \cdot u) I-\frac{2}{3} \rho K I\right]+F
\end{gathered}
$$

As the domain is a Tubular U-loop pipe, to get a better prediction about the flow around the curve region, we consider the $k$ - $\omega$ turbulent model. The parameters $k$ and $\omega$ are given by the following equations.

$$
\begin{gathered}
\rho(u \cdot \nabla) k=\nabla \cdot\left[\left(\mu+\mu_{T} \sigma_{k}^{*}\right) \nabla_{k}\right]+p_{k}-\rho \beta^{*} k \omega \\
\rho(u \cdot \nabla) \omega=\nabla \cdot\left[\left(\mu+\mu_{T} \sigma_{\omega}\right) \nabla \omega\right]+\alpha \frac{\omega}{k} p_{k}-\rho \beta \omega^{2} \\
\mu_{T}=\rho \frac{k}{\omega} \\
p_{k}=\mu_{T}\left[\nabla u:\left(\nabla u+(\nabla u)^{\mathrm{T}}\right)-\frac{2}{3}(\nabla \cdot u)^{2}-\frac{2}{3} \rho k \nabla \cdot u\right.
\end{gathered}
$$

The heat transfer rate through a fluid is governed by the following equation:

$$
\rho C_{p}\left(\frac{\partial T}{\partial t}+(u \cdot \nabla) T\right)=-(\nabla \cdot q)+\tau: S-\left.\frac{T}{\rho} \frac{\partial \rho}{\partial t}\right|_{p}\left[\frac{\partial \rho}{\partial t}+(u \cdot \nabla) p\right]+Q
$$

where,

$$
S=\frac{1}{2}(\nabla u+(\nabla u) T)
$$

Here in Equation (7), $Q$ contains heat source other than viscous heating (SI unit: $\mathrm{W} / \mathrm{m}^{3}$ ). For obtaining the heat transfer term used Fourier law of heat conduction, the convective heat flux, $\mathrm{q}$ is proportional to the temperature gradient.

$$
q_{i}=-K \frac{\partial T}{\partial x_{i}}
$$

where $K$ is the thermal conductivity. The convective heat flux is given by

$$
q_{i}=-\sum_{j} K_{i j} \frac{\partial T}{\partial x_{i}}
$$

The term $\tau: S$ in Equation (7) represents viscous heating of a fluid can be written in the following form:

$$
\tau: S=\sum_{m} \sum_{n} \tau_{m n} S_{m n}
$$

The term $\left.\frac{T}{\rho} \frac{\partial \rho}{\partial T}\right|_{p}\left[\frac{\partial \rho}{\partial t}+(u \cdot \nabla) p\right]$ represents a pressure work is responsible for the heating of a fluid under adiabatic compression and for some thermoacoustic effects. 
By using the Equations (7) and (8) we find

$$
\rho C_{p}\left[\frac{\partial T}{\partial t}+\rho C_{p}(u \cdot \nabla) T\right]=\nabla \cdot(k \nabla T)+Q
$$

If the velocity is to zero the equation becomes

$$
\rho C_{p} \frac{\partial T}{\partial t}+\nabla \cdot(-k \nabla T)=Q
$$

Again we obtain convective heat transfer coefficient

$$
h=\frac{Q}{T_{w}-T_{b}}
$$

where $T_{w}$ and $T_{b}$ are the wall and bulk temperature respectively and $T_{b}=\frac{T_{\text {out }}+T_{\text {in }}}{2}$, The Nusselt number is calculated by

$$
N u=\frac{h D}{k}
$$

Here $D$ is the diameter of the tube. Depended on the numerically measured pressure drop, the Darcy friction factor can be computed as following [21] [22]:

$$
\Delta p=h \rho g
$$

where $\Delta p$ is pressure drop and head loss is $\mathrm{h}$,

$$
h=\frac{f l u^{2}}{2 g D}
$$

From Equation (14) and (15) we have

$$
\Delta p=\frac{l}{D} \cdot \frac{f u^{2} \rho}{2}
$$

where, $\Delta p$ is the pressure drop across the length of the tube l. The performance Evaluation Criterion (PEC) is defined as follows [23]:

$$
\eta=\frac{\frac{N u}{N u_{0}}}{\left(\frac{f}{f_{0}}\right)^{\frac{1}{6}}}
$$

where $N u_{0}$ and $f_{0}$ are the Nusselt number and the friction factor of the plain tube respectively.

\section{Boundary Conditions}

In this flow model, the boundary conditions are assumed a different velocity for Reynolds number at the inlet and temperature of the fluid is $T=T_{\text {in }}=293.15 \mathrm{~K}$. The no-slip condition i.e. $u=0$, where $u_{\text {tang }}$ is the tangential velocity, at the inner wall of the tube and the wall function at the outlet of the domain governed by the following equations.

$$
u \cdot n=0
$$




$$
\begin{gathered}
{\left[\left(\mu+\mu_{T}\right)\left(\nabla u+(\nabla u)^{\mathrm{T}}\right)-\frac{2}{3}\left(\mu+\mu_{T}\right)(\nabla \cdot u) I-\frac{2}{3} \rho k I\right] n=-\rho \frac{u_{\tau}}{\delta_{w}} u_{\text {tang }}} \\
u_{\text {tang }}=u-(u \cdot n) n \\
\nabla k \cdot n=0, \omega=-\rho \frac{c_{\mu} K^{2}}{K_{v} \delta_{w} \mu}
\end{gathered}
$$

\section{Computational Domain and Mesh Design}

Design of computational domain with a twist ratio 3.5, and a twisted tape are shown in Figures 1(a)-(c). In our simulation, we have considered a typical U-loop circular tube whose length is $1875.08 \mathrm{~mm}$, inner diameter $26.6 \mathrm{~mm}$, outer diameter $33 \mathrm{~mm}$. The dimension of the insert is thickness $2 \mathrm{~mm}$, breadth 26 $\mathrm{mm}$ and length $120 \mathrm{~mm}$ in each strip. To reach a satisfactory computational exactness we continually change the mesh design until the outcomes obtained. As our domain length is large thus computer processor capacity becomes a significant issue for the computational study. The fine mesh is used along with the whole computational model for numerical simulation. We used 16 GB DDR3 RAM, Intel Core i7 processor-based computer for our simulation. The dimension of the twisted tape, mesh design of the inlet and mesh domain of the pipe are shown in Figure 1(d) \& Figure 1(e). A comparison of mesh design among different twist ratios $[2.9,3.0,3.25,3.5$ and 4.0$]$ insert combinations have shown in Table 1 and Table 2 respectively.

\section{Numerical Results}

The main aim of our numerical simulation is to ensure the enhancement of heat transfer phenomenon in a U-loop tubular pipe for a non-isothermal turbulent flow considered the twist ratio. The simulation is taken for independent of time. For this investigation, the thickness of the tube is neglected and the boundary conditions for the tube are being measured as a uniform heat flux adjoining the water domain layer. As we have only given attention to improving the heat transfer rate by the flowing fluid thus we ignored the flow of heat in the solid tube. We considered water as our working fluid. To realize the effect of inserts into the heat transfer phenomenon, we carried out the simulations by various types of twisted ratio and the twist ratios are 2.9, 3.0 3.25, 3.50 and 4.0 respectively.

Figures 2(a)-(e) shows the result for the twist ratio 3.5 in our simulation. From the simulation results, we set the initial temperature in the inlet is 293.15 $\mathrm{K}$. We observed that the outlet temperature $295.96 \mathrm{~K}$ for the Reynolds number 5000. If we increase the Reynolds number gradually to $10,000,15,000,20,000$ and 25,000 the maximum temperature were obtained $295.15 \mathrm{~K}, 294.59 \mathrm{~K}, 294.31$ $\mathrm{K}$ and $294.22 \mathrm{~K}$ respectively. On the basis of the simulation, we found that if we increased the Reynolds number the temperature is decreased for a uniform heat flux environment. 


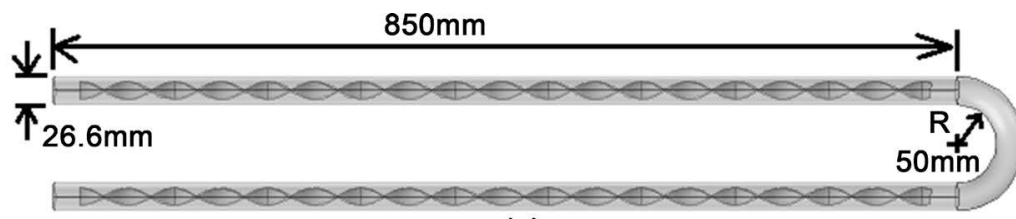

(a)

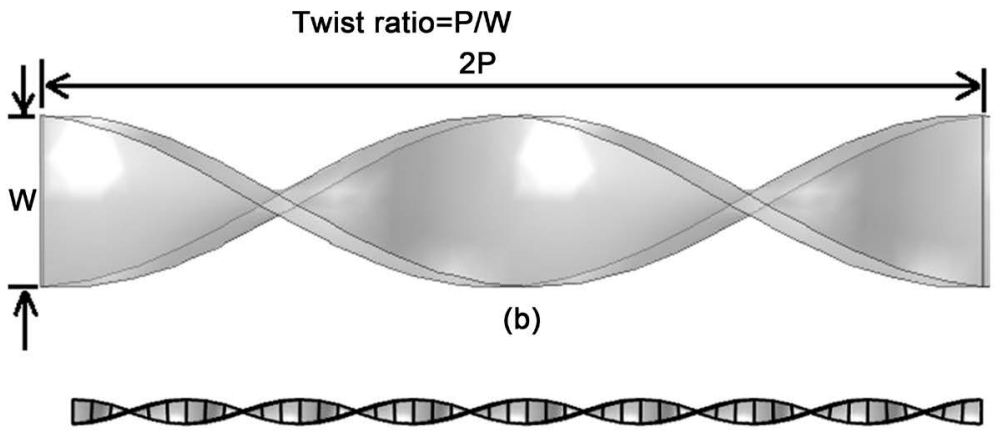

(c)

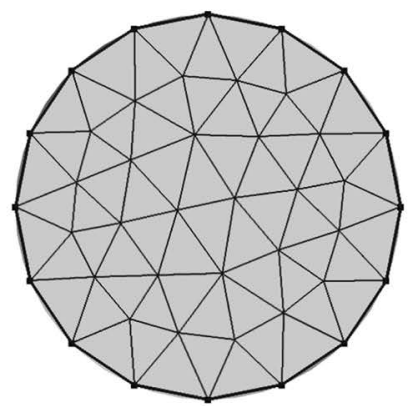

(d)

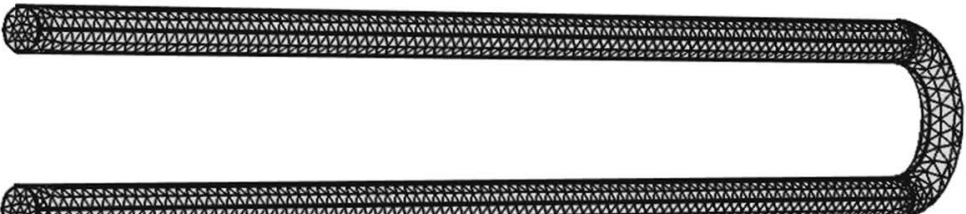

(e)

Figure 1. The computational domain (a) with insert, (b) measurement of twisted ratio, (c) full length twist domain, (d) cross-section of mesh design, (e) mesh design with inserts.

Table 1. Finer Mesh elements comparison of a tubular U-loop pipe with different twist ratios of inserts.

\begin{tabular}{cccccc}
\hline \multirow{2}{*}{ Property Name } & \multicolumn{5}{c}{ Twist Ratio (TR) } \\
\cline { 2 - 6 } & $\mathbf{2 . 9}$ & $\mathbf{3 . 0}$ & $\mathbf{3 . 2 5}$ & $\mathbf{3 . 5 0}$ & $\mathbf{4 . 0}$ \\
\hline Tetrahedral elements & 89,885 & 86,353 & 87,108 & 96,961 & 244,353 \\
Triangular elements & 23,946 & 23,404 & 23,478 & 23,474 & 40,446 \\
Edge elements & 3044 & 2980 & 2928 & 2896 & 4757 \\
Vertex elements & 92 & 92 & 84 & 84 & 164 \\
Minimum element quality & 0.04552 & 0.05882 & 0.05256 & 0.1128 & 0.02404 \\
Average element quality & 0.7031 & 0.6993 & 0.6992 & 0.7007 & 0.6937 \\
Element volume ratio & 0.01212 & 0.008956 & 0.007705 & 0.009335 & $1.058 \mathrm{E}-4$ \\
Mesh volume m & & & & & \\
\end{tabular}


Table 2. Extra fine Mesh elements comparison of a tubular U-loop pipe with different twist ratios of inserts.

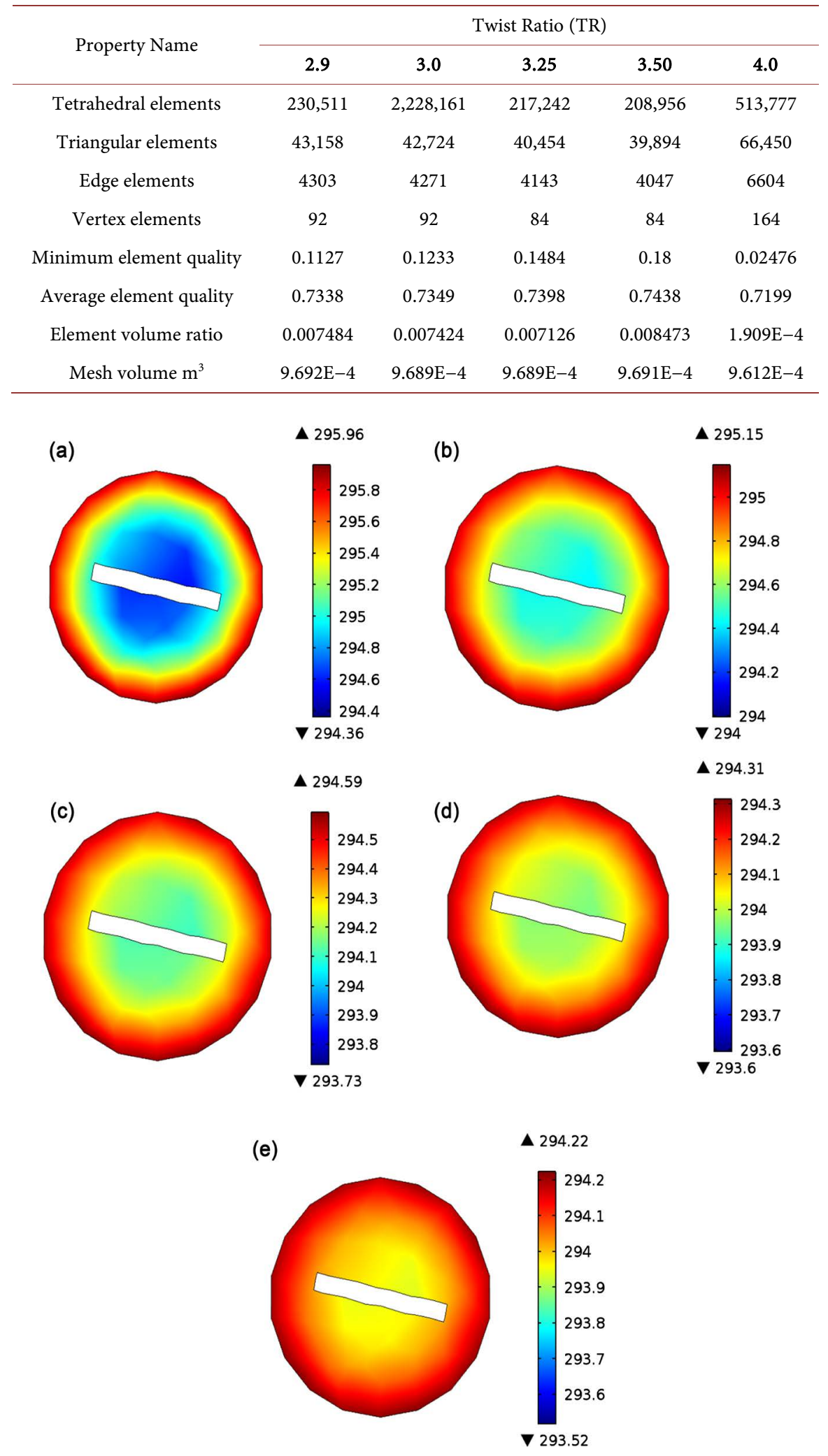

Figure 2. The temperature distributions of twist ratio 3.5 with different Reynolds number (a) $\operatorname{Re}=5000$, (b) $\operatorname{Re}=10,000$, (c) $\operatorname{Re}=15,000$, (d) $\operatorname{Re}=20,000$, (e) $\operatorname{Re}=25,000$. 


\subsection{Temperature Performance Evaluation}

Besides the twist ratio 3.5 we also have investigated for all ratios like 2.9, 3.0, $3.25,3.5$ and 4.0 to check the heat transfer phenomena in different twist ratio. We found different results are shown in Figure 3. This figure represents the temperature variation with the increment of Reynolds numbers for different twist ratios. For the twist ratio 3.5, we observe a gradual temperature fall with the increase of Reynolds numbers. We observed the same pattern for ratio 2.9 and 3.0 while 3.25 and 4.0. It is shown quite the opposite pattern though both are decreased. It seems 3.5 is the best twist ratio and the saturated level for the maximum heat transfer.

\subsection{Nusselt Number Performance Evaluation}

In terms of Nusselt Number (Nu) with Reynolds number (Re), the heat transfer variations are presented in Figure 4. Here we found that Nusselt number is increased with the Reynolds number for all the ratios. At a given Reynolds number with the twist ratio 3.5 yields higher Nusselt number than the other twist ratio. Figure 4 also shows the effect of twist ratios for heat transfer. We also observed that the Nusselts number increases with decreasing twist ratio. The twisted tape inserts with smaller twist ratio processes more twist numbers and shows better Nusselt numbers $(\mathrm{Nu})$. This creates higher turbulent intensity and consequently gives better heat transfer. From the simulation result of range, the uses of the twist ratio 3.5 provide higher Nusselt number than the ratios 2.9, 3.0, 3.25 and 4.0 respectively [6] [8].

\subsection{Friction Factor Performance Evaluation}

The variation of pressure drop in terms of friction factor (f) with Reynolds

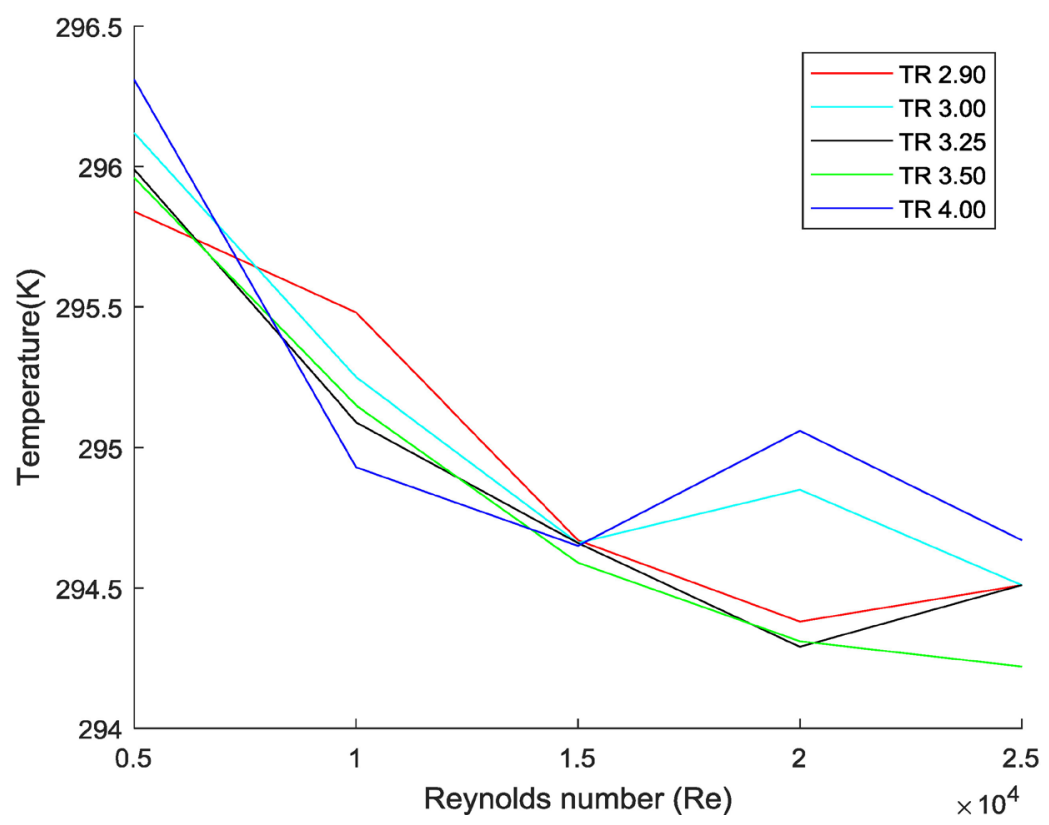

Figure 3. Temperature distribution with Reynolds number. 


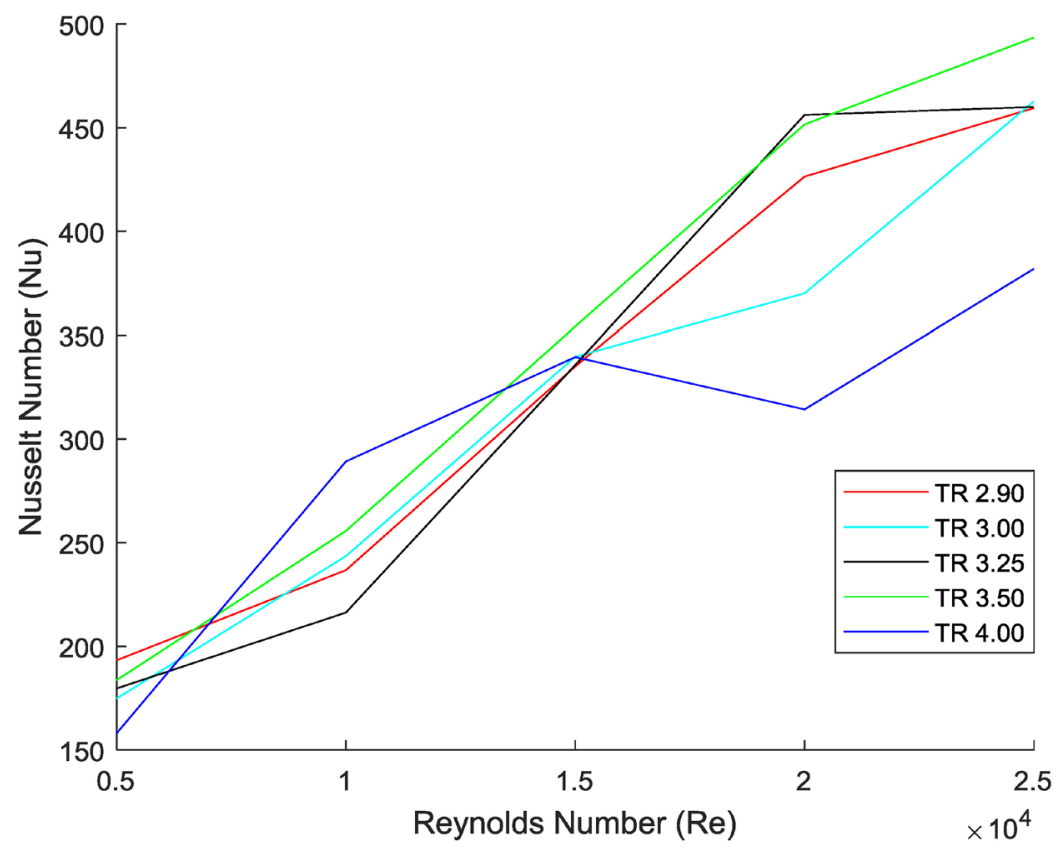

Figure 4. Effect of Nusselt number along with Reynolds number for different twist ratios (TR 2.90, 3.0, 3.25, 3.5 and 4.0).

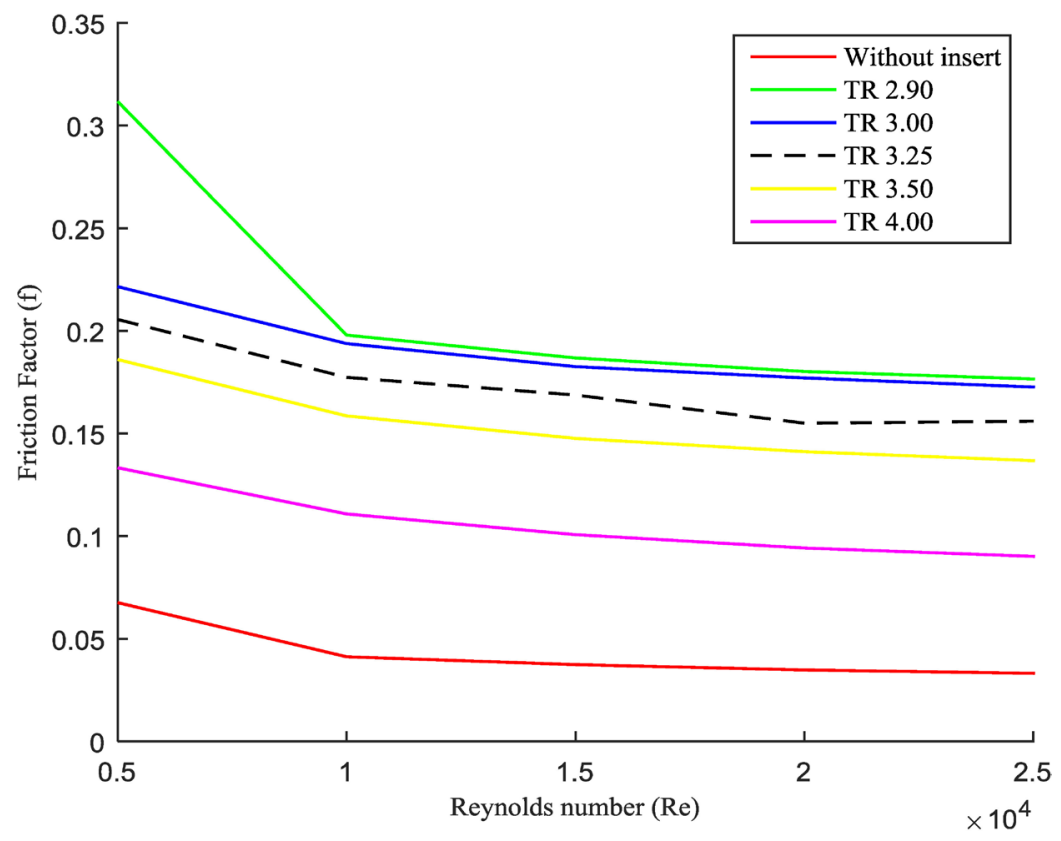

Figure 5. Combined graph of friction factor with Reynolds number.

number $(\mathrm{Re})$ is described in Figure 5. From Figure 5 we also observed that the friction factor tends to increase with decreasing twist ratios for all Reynolds number within the range. The twisted tape with inserts with smaller twist ratio process more twist numbers thus induces more consistent with stronger swirl intensity. This creates higher turbulent intensity and consequently better heat transfer. The favorable reduction of friction factor as compared with the ratio $2.9,3.0,3.25,4.0$, the twist ratio is 3.5 because of the lower flow scattering caused 
by the weaken swirl intensity effect of friction with Reynolds number for different twist ratios, which follow the result of S. Eiamsa-ard of convective heat transfer in a circular tube with short-length twisted tape insert.

\subsection{Thermal Performance Evaluation Criterion (PEC)}

The performance evaluation criterion (PEC) in a tube fitted with different twisted tapes obtained using numerical simulations are shown in Figure 6. It is observed that the PEC value tends to increase with increasing Reynolds number for 5000 to 10,000 but it's shown in different behavior for 15,000 to 25,000 . The tubes fitted with twisted tapes inserts of the ratio gives better overall heat transfer performance than the tubes with twisted tapes of the other twist ratios [2.9, $3.0,3.25$ and 4.0$]$.

\section{Conclusion}

A computational study of the heat transfer phenomenon of fluid flow through a tubular pipe with five different twist ratios $[2.9,3.0,3.25,3.5$ and 4.0] for a non-isothermal turbulent flow has been studied. The water consider as working fluid in our study and the initial temperature is assumed at the inlet is $293.15 \mathrm{~K}$. A no-slip condition on the wall and wall function on the outlet is assumed. For our simulation, we assumed that better heat transfer rate is found while the twist ratio is 3.5 compared with other ratios while the Reynolds number gradually increased from 5000 to 25,000. We found the same scenario for the Nusselts number as well. Also, we have observed that for pressure is reducing when the Reynolds $(\mathrm{Re})$ numbers are increased.

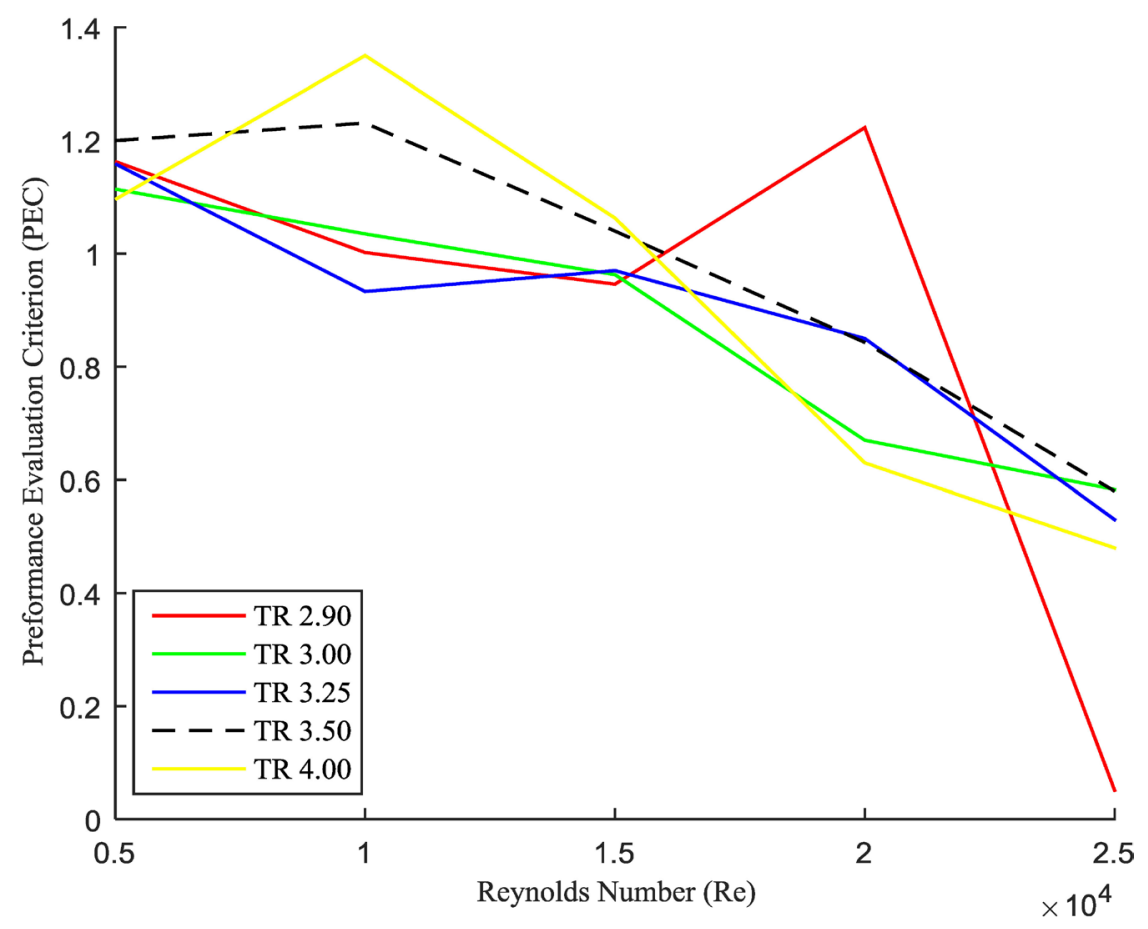

Figure 6. Combined graph of performance criterion with Reynolds number. 


\section{Acknowledgements}

The authors gratefully acknowledge the technical support provided by the Centre of Excellence in Mathematics, Department of Mathematics, Mahidol University, Bangkok 10400, Thailand and the simulation lab, Department of Mathematics, Chittagong University of Engineering \& Technology, Chittagong, Bangladesh.

\section{Conflicts of Interest}

The authors declare no conflicts of interest regarding the publication of this paper.

\section{References}

[1] Bergles, A.E. and Webb, R.L. (1985) A Guide to the Literature on Convective Heat Transfer Augmentation. Advance Enhanced Heat Transfer, 43, 81-89.

[2] Agarwalt, S.K. and Rao, M.R. (1996) Heat Transfer Augmentation for the Flow of a Various Liquid in Circular Tubes Using Twisted Tape Inserts. International Heat and Mass Transfer, 39, 3547-3557. https://doi.org/10.1016/0017-9310(96)00039-7

[3] Manglik, R.M. and Bergles, A.E. (1991) Heat Transfer Enhancement of in Tube Flows in Process Heat Exchangers by Means of Twisted-Tape Inserts. Heat Transfer Laboratory, Report No. HTL-8, Rensselaer Polytechnic Institute, Troy, New York.

[4] Ray, S. and Date, A.W. (2003) Friction and Heat Transfer Characteristics of Flow through Square Duct with Twisted Tape Insert. International Journal of Heat and Mass Transfer, 46, 889-902. https://doi.org/10.1016/S0017-9310(02)00355-1

[5] Bas, H. and Ozceyhan, V. (2012) Heat Transfer Enhancement in a Tube with Twisted Tape Inserts Placed Separately from the Tube Wall. Experimental Thermal and Fluid Science, 41, 51-58. https://doi.org/10.1016/j.expthermflusci.2012.03.008

[6] Akhavan-Behabadi, M. (2009) Effect of Twisted Tape Insert on Heat Transfer and Pressure Drop in Horizontal Evaporators for the Flow of R-134a. International Journal of Refrigeration, 32, 922-930. https://doi.org/10.1016/j.ijrefrig.2008.11.004

[7] Eiamsa-ard, S., Thaingpong, C., Eiamsa-ard, P. and Promvinge, P. (2009) Convective Heat Transfer in a Circular Tube with Short-Length Twisted Tape Insert. International Communication in Heat and Mass Transfer, 36, 365-371. https://doi.org/10.1016/j.icheatmasstransfer.2009.01.006

[8] Zozulya, N. and Shkuratov, I.Y. (1974) Effect of the Length of a Twisted-Tape Turbulence Promoter and of Its Initial Twisting Pitch of Augmenting of Heat Transfer Inside a Tube. Heat Transfer-Soviet Research, 6, 98-100.

[9] Wang, L. and Sunden, B. (2002) Performance Comparison of Some Tube Inserts. International Communications in Heat and Mass Transfer, 29, 45-56. https://doi.org/10.1016/S0735-1933(01)00323-2

[10] Noothong, W., Eiamsa-Ard, S. and Promvonge, P. (2006) Effect of Twisted-Tape Inserts on Heat Transfer in a Tube. International Conference on Sustainable Energy and Environment, A-030(P).

[11] Murugesan, P. (2009) Heat Transfer and Pressure Drop Characteristics of Turbulent Flow in a Tube Fitted with Trapezoidal-Cut Twisted Tape Insert. International Journal of Academic Research, 1, 123-128.

[12] Eiamsa-Ard, S. (2010) Influence of Combined Non-Uniform Wire Coil and Twisted 
Tape Inserts on Thermal Performance Characteristics. International Communications in Heat and Mass Transfer, 37, 850-856.

https://doi.org/10.1016/j.icheatmasstransfer.2010.05.012

[13] Sarada, S.N. (2010) Enhancement of Heat Transfer Using Varying Width Twisted Tape Inserts. International Journal of Engineering Science and Technology, 2, 107-118. https://doi.org/10.4314/ijest.v2i6.63702

[14] Murugesan, P., Malyilsamy, K., Suresh, S. and Srinivasan, P.S.S. (2011) Heat Transfer and Pressure Drop Characteristics in a Circular Tube Fitted with and without V-Cut Twisted Tape Insert. International Communications in Heat and Mass Transfer, 38, 329-334. https://doi.org/10.1016/j.icheatmasstransfer.2010.11.010

[15] Guo, J., Fan, A., Zhang, X. and Liu, W. (2011) A Numerical Study on Heat Transfer and Friction Factor Characteristics of Laminar Flow in a Circular Tube Fitted with Center-Cleared Twisted Tape. International Journal of Thermal Sciences, 50, 1263-1270. https://doi.org/10.1016/j.ijthermalsci.2011.02.010

[16] Salam, B., Biswas, S., Saha, S. and Bhuiya, M.M.K. (2013) Heat Transfer Enhancement in a Tube Using Rectangular-Cut Twisted Tape Insert. Procedia Engineering, 56, 96-103. https://doi.org/10.1016/j.proeng.2013.03.094

[17] Sivakumar, K. (2015) Experimental Investigation of Twisted Tape Insert on Laminar Flow with Uniform Heat Flux for Enhancement of Heat Transfer. Journal of Chemical and Pharmaceutical Sciences, 974, 2115-2126.

[18] Zhu, J.D. and Chen, H. (2015) Numerical Study on Enhanced Heat Transfer by Twisted Tape Inserts inside Tubes. Procedia Engineering, 130, 256-262. https://doi.org/10.1016/j.proeng.2015.12.219

[19] Bhattacharyya, S., Chattopadhyay, H. and Haldar, A. (2018) Design of Twisted Tape Turbulator at Different Entrance Angle for Heat Transfer Enhancement in a Solar Heater. Beni-Suef University Journal of Basic and Applied Sciences, 7, 118-126. https://doi.org/10.1016/j.bjbas.2017.08.003

[20] Cuvelier, C., Segal, A. and Van Steenhoven, A.A. (1986) Finite Element Methods and Navier-Stokes Equations. D. Reidel Publishing Company, Holland.

[21] White, F.M. (1998) Fluid Mechanics. 4th Edition, McGraw-Hill Company, New York.

[22] Piriyarungrod, N., Eiaamsaard, S., Thainpong, C., Pimsarn, M. and Nanan, K. (2015) Heat Transfer Enhancement by Tapered Twisted Tape Inserts. Chemical Engineering and Processing, 96, 62-71. https://doi.org/10.1016/j.cep.2015.08.002

[23] Fan, J.F., Ding, W.K., Zhang, J.F., He, Y.L. and Tao, W.Q. (2009) A Performance Evaluation Plot of Enhanced Heat Transfer Techniques. International Journal Heat Mass Transfer, 52, 33-44. https://doi.org/10.1016/j.ijheatmasstransfer.2008.07.006 